OPEN ACCESS

Edited by:

Qiaobao Zhang,

Xiamen University, China

Reviewed by:

志聪施,

Guangdong University of Technology,

China

Huixin Chen,

Xiamen Institute of Rare Earth

Materials, China

Jianmin Ma,

Hunan University, China

*Correspondence: Hua Cheng

chengh@sustc.edu.cn

Zhouguang Lu

luzg@sustc.edu.cn

Specialty section:

This article was submitted to

Nanoscience,

a section of the journal

Frontiers in Chemistry

Received: 15 May 2018

Accepted: 15 June 2018

Published: 06 July 2018

Citation:

Yu S, Wan Y, Shang C, Wang Z,

Zhou L, Zou J, Cheng H and LU Z

(2018) Ultrafine $\mathrm{NaTi}_{2}\left(\mathrm{PO}_{4}\right)_{3}$

Nanoparticles Encapsulated in

N-CNFs as Ultra-Stable Electrode for

Sodium Storage. Front. Chem. 6:270.

doi: 10.3389/fchem.2018.00270

\section{Ultrafine $\mathrm{NaTi}_{2}\left(\mathrm{PO}_{4}\right)_{3}$ Nanoparticles Encapsulated in N-CNFs as Ultra-Stable Electrode for Sodium Storage}

\author{
Sicen Yu, Yi Wan, Chaoqun Shang, Zhenyu Wang, Liangjun Zhou, Jianli Zou, Hua Cheng* \\ and Zhouguang Lu*
}

Department of Materials Science and Engineering, Southern University of Science and Technology, Shenzhen, China

We present a feasible method for the preparation of one-dimensional $\mathrm{N}$-doping carbon nanofibers encapsulated $\mathrm{NaTi}_{2}\left(\mathrm{PO}_{4}\right)_{3}$ (NTP-NCNFs) through electrospinning accompanied by calcination. The poor electrical conductivity of NTP is significantly improved and the as-prepared NTP-NCNFs exhibit stable and ultrafast sodium-storage capability. The NTP-NCNFs maintains a stable specific capacity of $121 \mathrm{mAh} \mathrm{g}^{-1}$ at $10 \mathrm{C}$ after 2,000 cycles, which only drop to $105 \mathrm{mAh} \mathrm{g}^{-1}$ after 20,000 cycles. Furthermore, the NTP-NCNFs show excellent rate performance from 0.2 to $20 \mathrm{C}$, whose recovery efficiency still reaches $99.43 \%$. The superior electrochemical property is mainly attributed to the large specific surface area, high porosity, N-doping carbon coating, and one-dimensional structure of NTP-NCNFs.

Keywords: NTP, N-doping carbon nanofibers, cycling performance, electrospinning, sodium-storage

\section{INTRODUCTION}

Because of the high energy density, stable cycling performance, and environmental benignity, Liion batteries have been widely applied in portable devices and electric vehicles (Duncan et al., 2016; Kim et al., 2016; Zhang et al., 2018; Zheng et al., 2018). However, the limited lithium mineral reserves restrict the wide application of LIBs in grid-scale energy storage system. As cost-effective alternatives to Li-ion batteries, sodium ion batteries have been investigated for next-generation energy storage system, benefiting from sodium abundance (Wu et al., 2016; Wang et al., 2017, 2018; Xu et al., 2017). SIBs basically have similar battery components and electrical storage mechanisms as LIBs. However, the poor electrochemical kinetics and large volume change caused by large size of $\mathrm{Na}$ ions leads to severe capacity loss and cycling degradation. Therefore, the challenge of looking for sodium storage materials with good stability and high-rate capacity still remains.

Recently, NTP as one of sodium super-ionic conductor (NASICON) has been demonstrated as potential long life-time and high-rate electrode material for SIBs (Guin and Tietz, 2015; Wu et al., 2015; Hu et al., 2018; Liang L. et al., 2018). The strong P-O covalent bond in the phosphates offers remarkable structural and thermal stability and the open three-dimensional (3D) framework in NTP allows for fast sodium ions transfer(Li et al., 2012; Yang et al., 2015; Wang et al., 2016). However, pristine NTP with low intrinsic electronic conductivity displays poor electrochemical performance. In order to address this issue, some strategies including nano-sizing the particle, coating a conductive layer on the surface, and mixing with high conductive materials have been proposed (Fang et al., 2016; Ha-Kyung et al., 2016; Liang et al., 2018b). Although significant 
enhancement has been achieved, the satisfactory electrochemical performance with high rate capability and stability of NTP is still of great urgent.

Electrospinning is a fascinating way to prepare CNFs (Li et al., 2017; Zhu et al., 2017; Liang et al., 2018a). Meanwhile, due to the presence of carbon and nitrogen source from the starting polymer, electrospinning can be adapted to a feasible preparation for N-doping carbon matrixes encapsulated NTP nanoparticles to realize high performance for sodium storage. Herein, NTP nanoparticles are embeded into conductive $\mathrm{N}$-doping carbon nanofibers (denoted as NTP-NCNFs). 1D nanofibers provide fast charge transfer pathway, ensuring the NTP-NCNFs with superb rate performance. The NCNFs matrix also contributes to the ultra-long cycling stability. At $10 \mathrm{C}$ rate, the NTP-NCNFs maintained a specific capacity of $105 \mathrm{mAh} \mathrm{g}^{-1}$ after 20,000 cycles.

\section{EXPERIMENTAL SECTION}

\section{Preparation of NTP-NCNFs}

$\mathrm{NaH}_{2} \mathrm{PO}_{4} \cdot 2 \mathrm{H}_{2} \mathrm{O} \quad(0.211 \mathrm{~g})$ and polyacrylonitrile (PAN) $(0.8 \mathrm{~g})$ were dissolved into $\mathrm{N}, \mathrm{N}$-dimethylformamide (DMF) $(10 \mathrm{ml})$ to obtain a homogeneous solution. Then, titanium tetraisopropanolate $\left[\left(\mathrm{CH}_{3} \mathrm{CH}_{3} \mathrm{CHO}\right)_{3} \mathrm{Ti}\right](0.5 \mathrm{ml})$ was dropped into above solution and stirred overnight. And then, the solution was injected into the syringe with a $21 \mathrm{G}$ needle, which the flow rate was $10 \mathrm{uL} \mathrm{min}{ }^{-1}$. Al foil was employed as the collector with distance to the needle of $15 \mathrm{~cm}$ and voltage of $15 \mathrm{kV}$. The as-electrospun fibers were carbonized in a tube furnace at $700^{\circ} \mathrm{C}$ (denoted as $700 \mathrm{NTP}-\mathrm{NCNFs}$ ), $800^{\circ} \mathrm{C}$ (denoted as $800 \mathrm{NTP}-\mathrm{NCNFs}$ ), $900^{\circ} \mathrm{C}$ (TiN) for $2 \mathrm{~h}$ under inert atmosphere. As a fair comparison, the $\mathrm{NaTi}_{2}\left(\mathrm{PO}_{4}\right)_{3}$ powder was synthesized via mixing the same ratio of $\mathrm{NaH}_{2} \mathrm{PO}_{4} \cdot 2 \mathrm{H}_{2} \mathrm{O}$ and $\left[\left(\mathrm{CH}_{3} \mathrm{CH}_{3} \mathrm{CHO}\right)_{3} \mathrm{Ti}\right]$ annealed at $800^{\circ} \mathrm{C}$ under argon atmosphere.

\section{Materials Characterization}

The crystal structure of the fibers was characterized using powder X-ray diffraction (XRD) on a Rigaku D/Max-2400 Xray diffractometer with $\mathrm{Cu}-\mathrm{K} \alpha$ radiation $(\lambda=1.54056 \AA)$. The specific surface area and the pore size distribution of as-prepared $\mathrm{N}$-doping carbon coating NTP nanofibers $\left(700\right.$ and $800^{\circ} \mathrm{C}$ ) were evaluated by the Brunauer-Emmet-Teller (BET) at $77 \mathrm{~K}$ using a NOVA 1200e Surface Area. Raman spectra of samples were acquired with a Lab RAM HR 800 Raman microscope with an excitation laser beam $(\lambda=532 \mathrm{~nm})$. SEM images were obtained on a scanning electron microscope (Hitachi, S4800) attached with an energy-dispersive X-ray spectroscopy (EDS) facility. TEM and HR-TEM images were recorded on a JEOL JEM-2010 (JEOL Ltd, Tokyo, Japan) at $200 \mathrm{kV}$. Ex-situ XPS records were performed on a VG scientific ESCALAB 250 spectrometer.

\section{Electrochemical Analysis}

The electrochemical properties of the $\mathrm{N}$-doping carbon coating NTP nanofibers was tested by assembling 2016 coin-type cells with $\mathrm{Na}$ as the counter electrode. NTP-NCNFs, Super P, and polyvinylidene fluoride (PVDF) binders dissolved in $\mathrm{N}$ methylpyrrolidone (NMP) were mixed into slurry with a weight ratio of $8: 1: 1$, which was coated on a $\mathrm{Cu}$ foil and dried in a vacuum oven at $110^{\circ} \mathrm{C}$ for $6 \mathrm{~h}$, further dividing into wafers with $12 \mathrm{~mm}$ diameter. The active material is about $0.64 \mathrm{mg}$ $\mathrm{cm}^{-2}$. The separator was a glass fiber filter. The electrolyte was $1 \mathrm{M} \mathrm{NaClO}_{4}$ /ethylene carbonate (EC) and propylene carbonate (PC) with volume ratio of $1: 1$. The specific capacity is based on the whole mass of NTP-NCNFs. Electrochemical capacity measurements of the NTP-NCNFs were tested on the Neware battery test system by applying galvanostatic charge-discharge. Cyclic voltammetry (CV) was performed on a BioLogicVMP3 electrochemical workstation at the same voltage window with a sweep rate of $0.1 \mathrm{mV} \mathrm{s}^{-1}$. Electrochemical impedance spectroscopy (EIS) was recorded at an AC voltage of $5 \mathrm{mV}$ amplitude in the frequency range from 1.0 to $100 \mathrm{mHz}$ at room temperature.

\section{RESULTS AND DISCUSSION}

Figure 1 depicts the synthesis of NTP-NCNFs. It should be noted that $\left(\mathrm{CH}_{3} \mathrm{CH}_{3} \mathrm{CHO}\right)_{3} \mathrm{Ti}$ was added into the mixture solution under vigorous stirring followed by electrospinning. Figures $2 \mathbf{a}, \mathbf{b}$

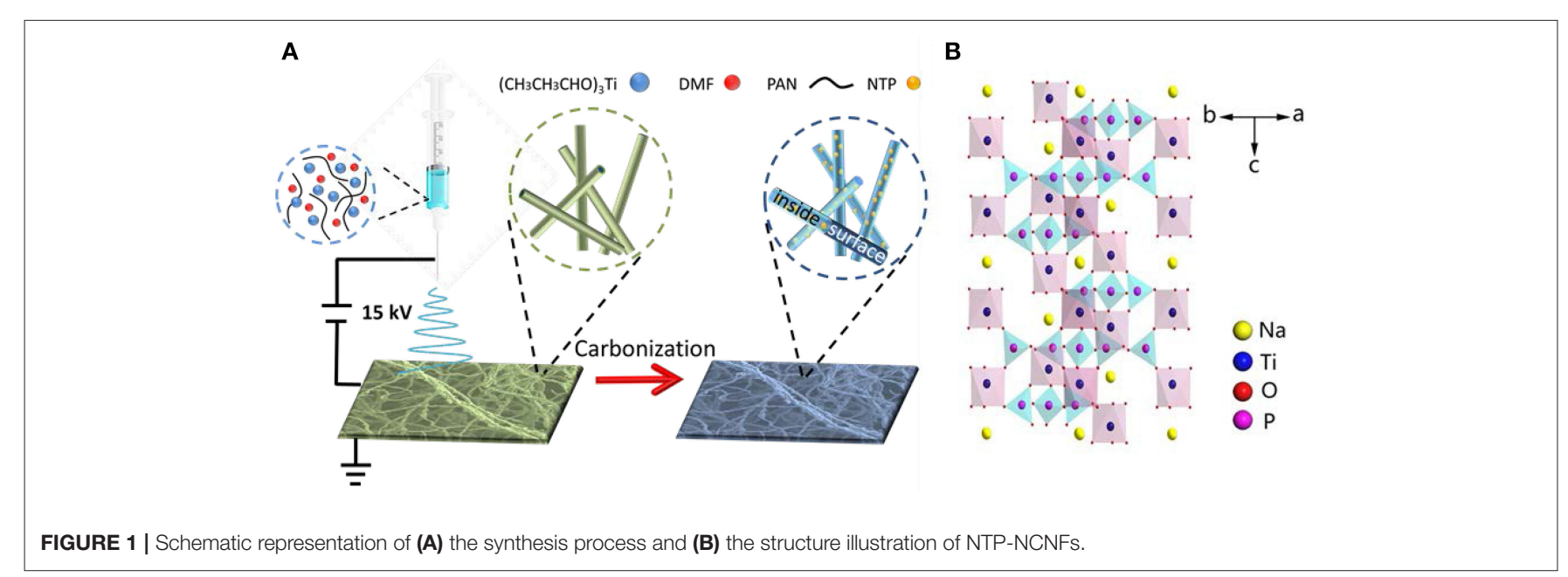



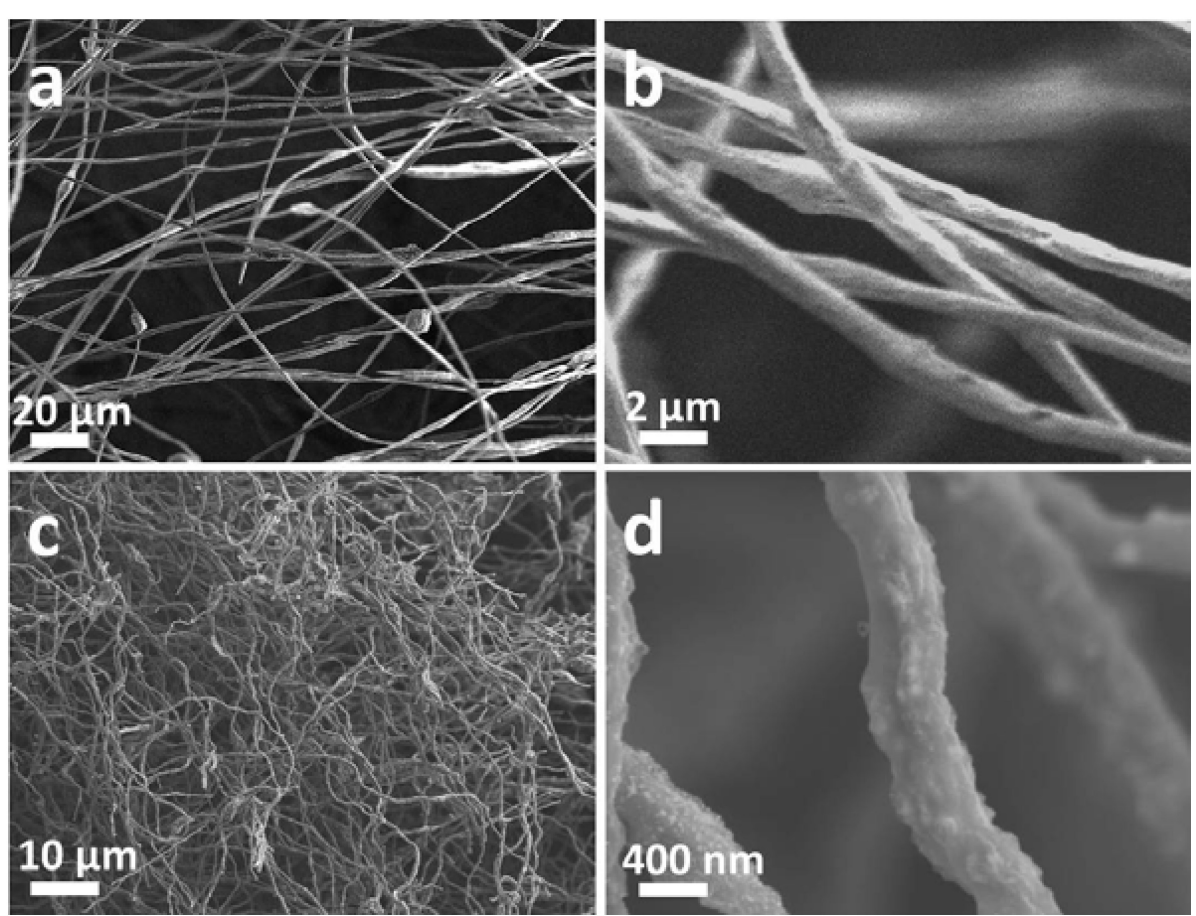

FIGURE 2 | SEM images of 800NTP-NCNFs before $\mathbf{( a , b )}$ and after $\mathbf{( c , d )}$ calcination.

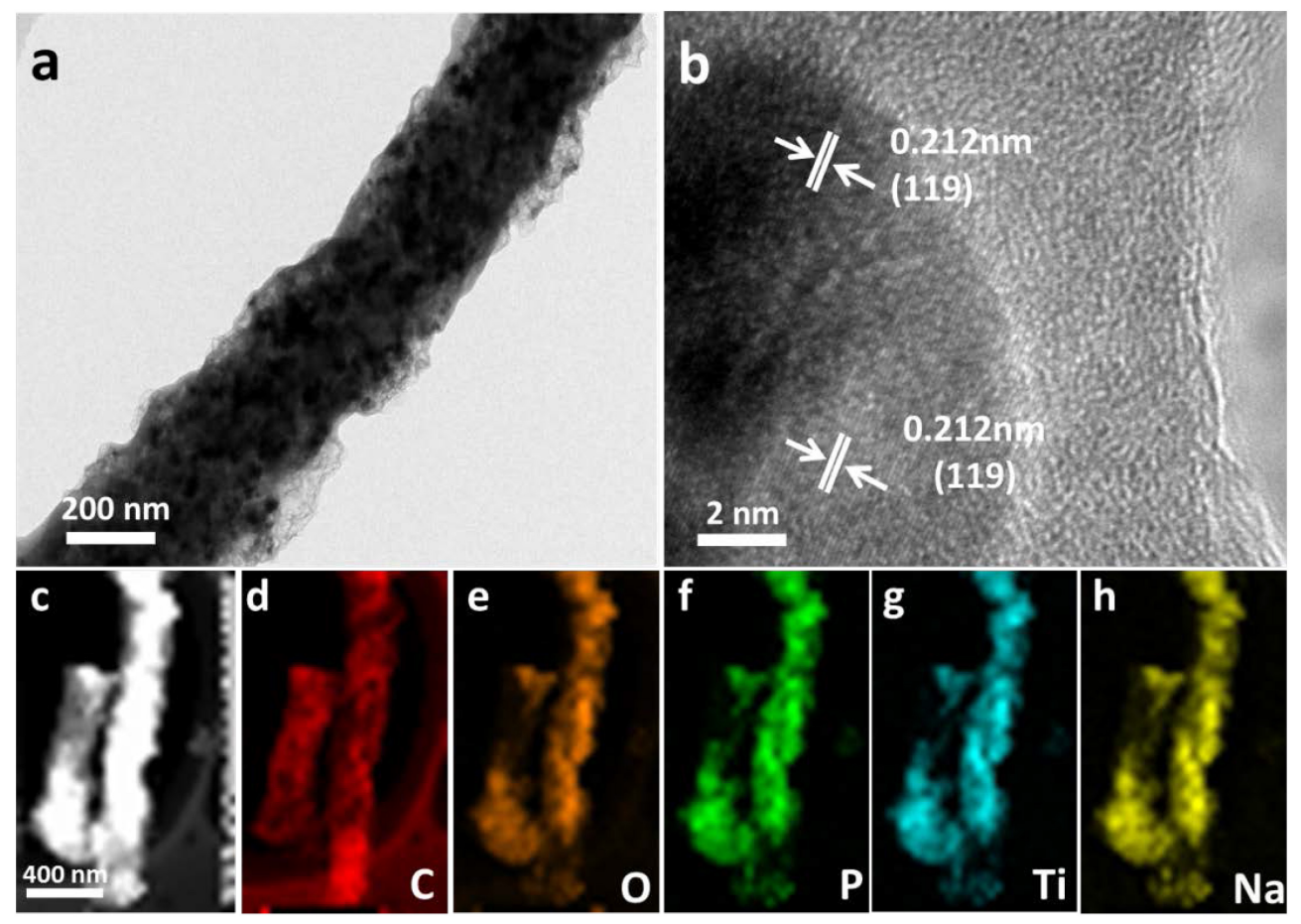

FIGURE 3 | (a) Typical TEM image and (b) HRTEM image of 800NTP-NCNFs, (c) HAADF/STEM image of 800NTP-NCNFs, and corresponding EDS elemental mapping images: (d) $\mathrm{C}$, (e) $\mathrm{O}$, (f) $\mathrm{P}$, (g) $\mathrm{Ti}$, and (h) $\mathrm{Na}$. 
show the continuous nanofibers with diameter of $\sim 500 \mathrm{~nm}$. The as-prepared nanofibers will be subjected to a calcination process under argon atmosphere at $800^{\circ} \mathrm{C}$, during which the PAN will convert into $\mathrm{N}$-doped carbon materials while keeping its 1D morphology (Wang et al., 2013). The result of thermogravimetric analysis shows that the mass ratio between $\mathrm{NaTi}_{2}\left(\mathrm{PO}_{4}\right)_{3}$ and $\mathrm{N}$-doped carbon materials is about 1:1 (Figure $\mathrm{S} 1)$. Meanwhile, the $\mathrm{NaH}_{2} \mathrm{PO}_{4}$ and $\left(\mathrm{CH}_{3} \mathrm{CH}_{3} \mathrm{CHO}\right)_{3} \mathrm{Ti}$ form NTP nanoparticles via a solid reaction process (Ribero et al., 2016; Wang et al., 2016). As shown in Figures 2c,d, the surface of the fiber become rough and evenly decorated by nanoparticles after calcination. However, after pyrolysis at $900^{\circ} \mathrm{C}$ in argon atmosphere, the as-prepared sample has changed to TiN (JCPDF\#65-0715) as demonstrated by the XRD analysis (Figure S2). This might be caused by the reduction of NTP at higher pyrolysis temperature by ammonia, which was formed by the decomposition of PAN (Liu et al., 2013). As-prepared TiN still keeps as nanofibers, shown in Figure S3. Though it is beneficial to the electrical conductivity of NTP-NCNFs, the further pyrolysis of carbon layer leads to a bad influence on its electrochemical performance, which was exhibited in Figure S4.
Therefore, the further research mainly focuses on 700/800NTPNCNFs.

High resolution TEM (HRTEM) measurements further confirmed the formation of NTP. Figure 3a shows that NTP nanoparticles evenly distributed over the carbon fiber. HRTEM (Figure $3 \mathbf{b}$ ) reveals the lattice fringes of $0.21 \mathrm{~nm}$, matching with the spacing of (119) plane of NTP. The elemental mapping using EDS coupled with HAADF/STEM was utilized to investigate the compositional distributions of $\mathrm{C}, \mathrm{O}, \mathrm{P}, \mathrm{Ti}$, and $\mathrm{Na}$ in 800 NTP-NCNFs (Figures $\mathbf{3 c}-\mathbf{h}$ ), which clearly shows that these elements are uniformly distributed in 800NTP-NCNFs. The uniform structure of $\mathrm{N}$-doping carbon matrix should improve the electrical conductivity of NTP.

Figure 4A shows the XRD patterns of NTP-NCNFs, in which all the peaks can be indexed to the standard NTP peaks (JCPDF\#33-1296). To clarify the degrees of defect structure and graphitization, Raman spectroscopy is carried out. As shown in Figure 4B, the D $\left(1,350 \mathrm{~cm}^{-1}\right)$ and $G\left(1,600 \mathrm{~cm}^{-1}\right)$ bands are significantly observed, which represents disordered and graphitization, respectively. The $\mathrm{I}_{\mathrm{D}} / \mathrm{I}_{\mathrm{G}}$ value of $800 \mathrm{NTP}-\mathrm{NCNF}$ is 1.05 , which is evidently lower than that of $700 \mathrm{NTP}-\mathrm{NCNF}$
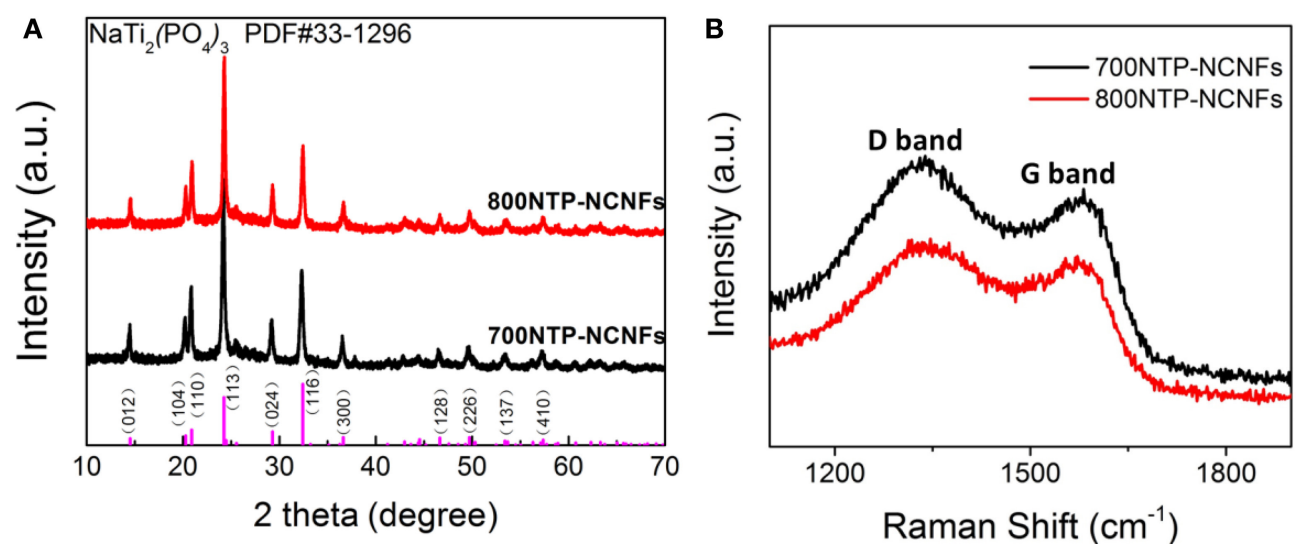

FIGURE 4 | (A) The X-ray diffraction patterns and (B) Raman spectrum of 700NTP-NCNFs and 800NTP-NCNFs.
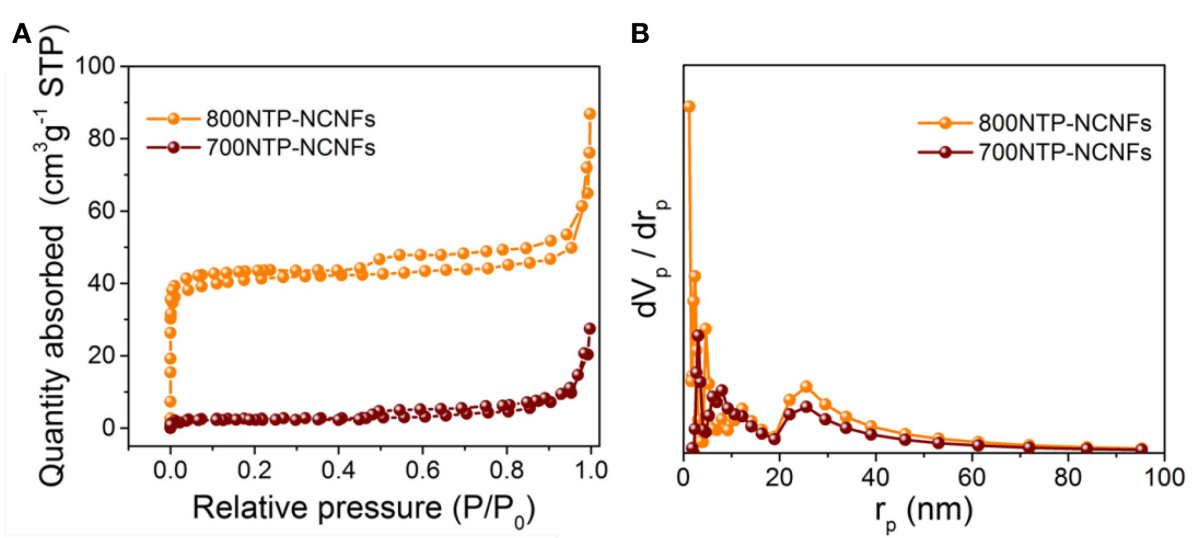

FIGURE 5 | (A) $\mathrm{N}_{2}$ absorption-desorption isotherm and (B) the pore-size distribution curves of the 700NTP-NCNFs and 800NTP-NCNFs. 
(1.14) (Wang et al., 2015). The significantly decreased value of $\mathrm{I}_{\mathrm{D}} / \mathrm{I}_{\mathrm{G}}$ indicates an enhanced degree of graphitization, which is likely beneficial to fast electron transport of NTP-NCNFs.

$\mathrm{N}_{2}$ adsorption and desorption isotherms (Figure 5A) of both 700NTP-NCNFs and 800NTP-NCNFs can be identified as type IV isotherms, with pronounced hysteresis loops, implying the mesopores in NTP-NCNFs. The BET surface area of 800NTP-NCNFs is $153.86 \mathrm{~m}^{2} \mathrm{~g}^{-1}$, which is much higher than that of $700 \mathrm{NTP}-\mathrm{NCNF}\left(\sim 10 \mathrm{~m}^{2} \mathrm{~g}^{-1}\right)$. The high BET surface area of $800 \mathrm{NTP}-\mathrm{NCNF}$ is likely due to the higher carbonization degree and the release of gas generated at higher pyrolysis temperature. The pore size distributions are shown in Figure 5B, which suggest the formation of micro-, meso-, and macro-pores. The larger specific surface area and hierarchical pore structures can effectively increase the mass transport and the contact between NTP and electrolyte, which would be beneficial to the electrochemical performance of the 800 NTP-NCNFs. Therefore, we believe that 800 NTP-NCNFs will have better electrochemical performance than 700NTP-NCNFs (Figure S5).

We first use cyclic voltammetry (CV) to investigate the sodium storage mechanism of 800NTP-NCNFs (Figure 6A). During the initial cathodic scan, the peaks at 0.81 and $0.51 \mathrm{~V}$ are higher than those of subsequent cycles, which are caused by the formation of solid electrolyte interface layer (SEI). Remarkably, nearly all the shape and the position of the peaks are overlap after the second CV curve, suggesting excellent electrochemical reversibility and stability of $800 \mathrm{NTP}-\mathrm{NCNF}$ for sodium storage.

The discharge-charge profiles of $800 \mathrm{NTP}-\mathrm{NCNF}$ are recorded at various rates (Figure $6 \mathrm{C}$ ). The plateaus at $\sim 2.1$
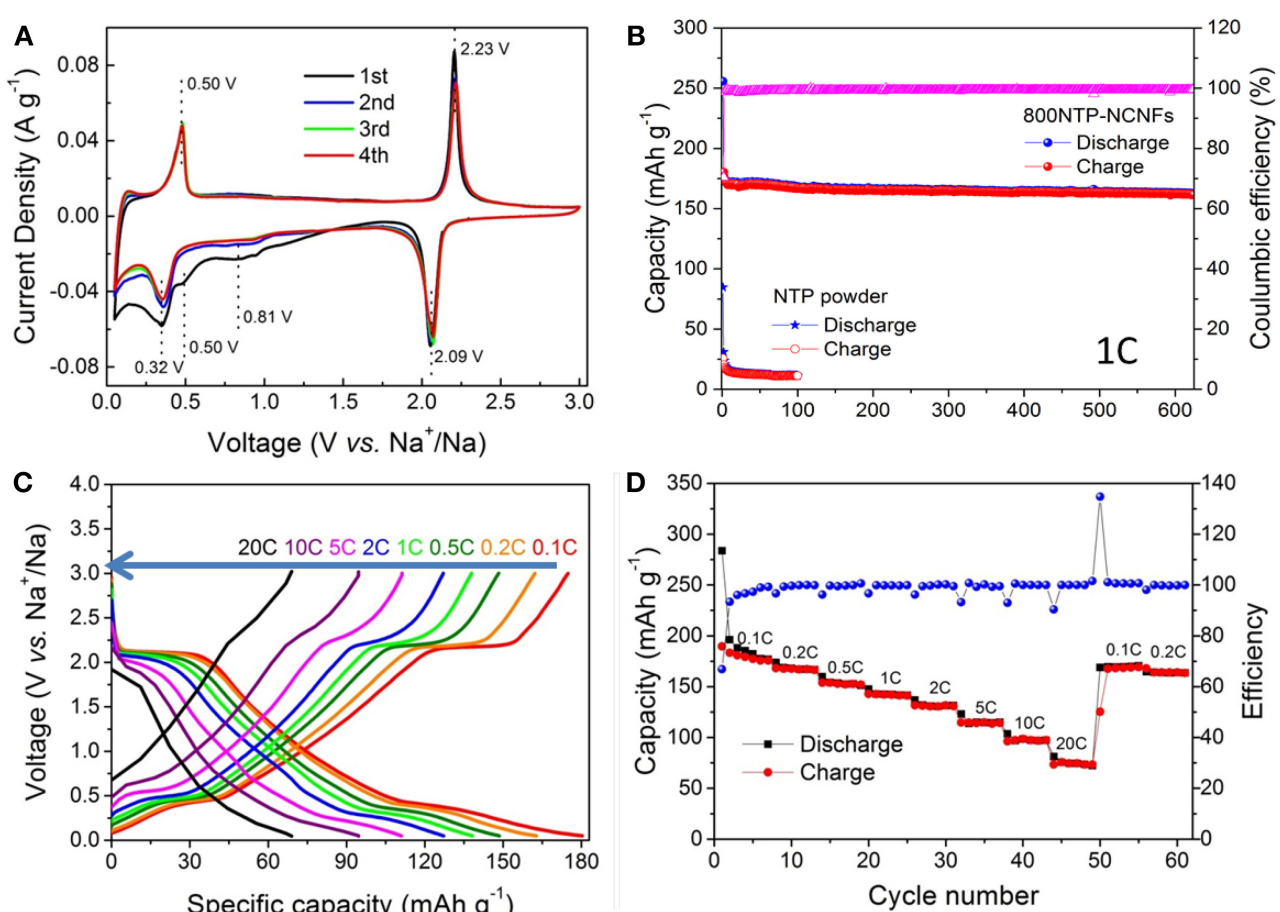

$\mathbf{E}$

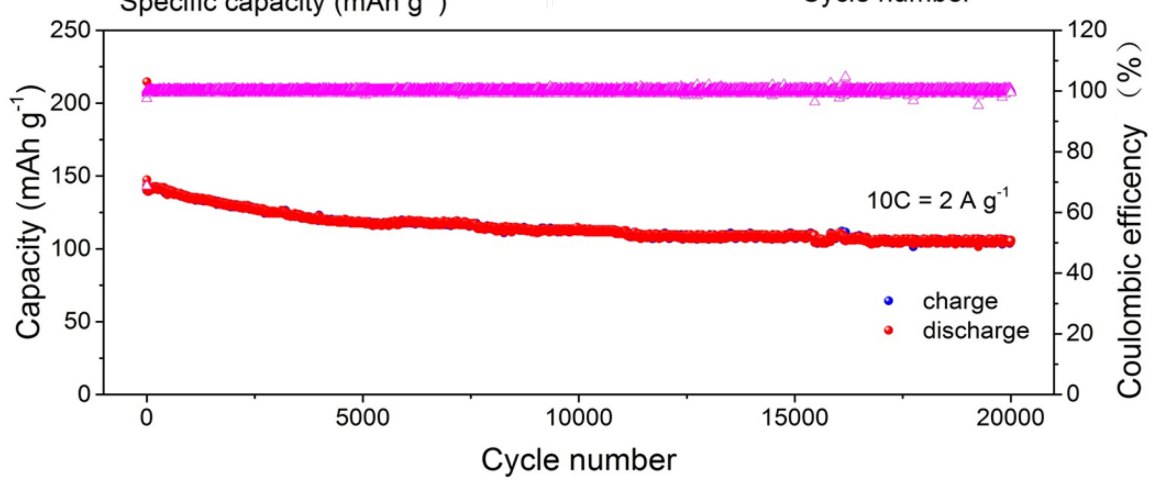

FIGURE 6 | Electrochemical performance of 800NTP-NCNFs: (A) CV curves for the initial 4 cycles, (B) the cycling performance at a current density of 200 mA $9^{-1}$ (1 C) and corresponding coulombic efficiency, (C) galvanostatic discharge-charge profiles at different current rates with initial discharge capacity excluded, (D) rate capability at different current rates ranging from 0.1 to $20 \mathrm{C}$ and back to $0.1-0.2 \mathrm{C}$, (E) cycle performance at high current density of $2 \mathrm{~A} \mathrm{~g}-1$ (10 C). 


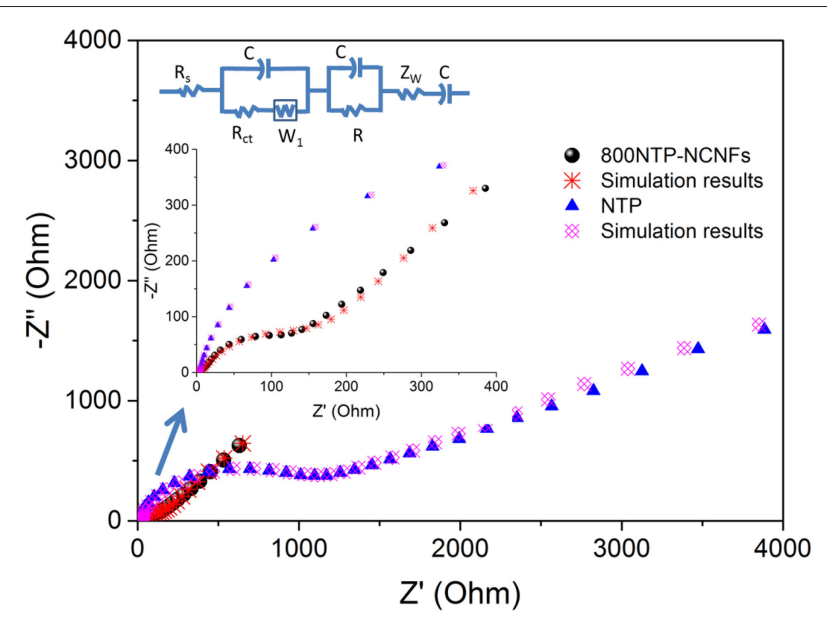

FIGURE 7 | Electrochemical impedance spectroscopy (EIS) measurements of 800NTP-NCNFs and pristine NTP powders.

and $\sim 0.32 \mathrm{~V}$ during discharge and plateaus at $\sim 0.5$ and $\sim 2.2 \mathrm{~V}$ during charge are in agreement with the CV results. Here, the NCNFs contribute to $\mathrm{Na}^{+}$storage and the overall specific capacity is based on the whole mass of 800 NTP-NCNFs (Stevens and Dahna, 2000; Dahbi et al., 2014).

Figure 6D shows the rate performance of $800 \mathrm{NTP}-\mathrm{NCNF}$ at different current densities. The reversible specific capacity was $176 \mathrm{mAh} \mathrm{g}^{-1}$ at $0.1 \mathrm{C}$. As the rate increased from 0.2 to $0.5,1$, $2,5,10$, and $20 \mathrm{C}$, the corresponding specific capacity was 163 , $149,138,127,110,95$, and $71 \mathrm{mAh} \mathrm{g}^{-1}$, with a capacity retention ration of $92.61,84.66,78.41,72.16,62.50,53.98$, and $40.34 \%$ as reference to that at $0.1 \mathrm{C}$, respectively. As the rate returned to $0.1 \mathrm{C}$, the specific capacity of $800 \mathrm{NTP}-\mathrm{NCNF}$ recovered to $175 \mathrm{mAh} \mathrm{g}^{-1}$, which demonstrated the excellent reversibility of $800 \mathrm{NTP}-\mathrm{NCNF}$ during $\mathrm{Na}^{+}$insertion and extraction. As illustrated in Figure 6E, the 800NTP-NCNFs deliver ultra-stable cycling performance and rate capability for 20,000 cycles at $10 \mathrm{C}$. The $800 \mathrm{NTP}-\mathrm{NCNF}$ maintain a stable specific capacity of $121 \mathrm{mAh} \mathrm{g}^{-1}$ after 2,000 cycles, which is about $80 \%$ of initial capacity. After 20,000 cycles, the 800NTP-NCNFs even deliver a considerable capacity of $105 \mathrm{mAh} \mathrm{g}^{-1}$. The astonishing electrochemical property of $800 \mathrm{NTP}-\mathrm{NCNF}$ is attributed to several features: (i) NASICON-structured NTP ensures sufficient ion transport; (ii) N-doping carbon coating on the surface of NTP improves the electronic conductivity of NTP, which provides fast electronic transport; (iii) 1D structure with large surface area ensures rapid ion transport by enhancing electrode and electrolyte contact; (iv) the hierarchical pore distribution is favorable for the electrolyte penetration and accommodation of volume change.

The 800NTP-NCNFs displayed superior cycling stability with high specific capacity to that of pristine NTP powder (Figure 6B), which further demonstrated that 800NTP-NCNFs intrinsically improved the electronic conductivity of NTP. To investigate the improvement of 800 NTP-NCNFs, EIS was performed in Figure 7. The charge-transfer resistance $\left(\mathrm{R}_{\mathrm{ct}}\right)$ for pristine NTP powder electrode is $1100 \Omega$, and this high resistance reflects the low intrinsic electrical conductivity of NTP. The $R_{c t}$ of 800 NTP-NCNFs is significantly lower than that of pristine NTP powder electrode (around $150 \Omega$ ), which implies that NTP encapsulated in N-doping carbon fiber structure successfully enhance the electrical conductivity and, in turn, the electrochemical performance of NTP (Figure 6B).

\section{CONCLUSION}

In summary, we presented a feasible method to prepare NTPNCNFs which exhibits excellent rate capability and stable cycling performance for sodium storage. The NTP-NCNFs could deliver a specific capacity of $105 \mathrm{mAh} \mathrm{g}^{-1}$ under $10 \mathrm{C}$ even after 20000 cycles. The nanosized NTP shorten the solid-state ion diffusion length and accelerate surface electrochemical reaction in the electrode. The 1D N-doped carbon coating enhances electronic conductivity of NTP and ensures the fast electron transfer. Moreover, the $3 \mathrm{D}$ woven network is beneficial to the penetration of electrolyte and accommodates the volume change of NTP during cycling.

\section{ASSOCIATED CONTENT}

\section{Supporting Information}

TGA curve of 800 NTP-NCNFs, XRD patterns of TiN, SEM and TEM images of TiN, and electrochemical performance of TiN and 700 NTP-NCNFs including CV curves for the initial 4 cycles and the cycling performance at a current density of $200 \mathrm{~mA} \mathrm{~g}^{-1}$ (1 C) and corresponding coulombic efficiency.

\section{AUTHOR CONTRIBUTIONS}

ZL and CS designed the research. CS, SY, YW, ZW, and LZ performed the experiments. JZ, HC, ZL, and CS incorporated in the interpretation of experimental results. All authors participated in the general discussion.

\section{ACKNOWLEDGMENTS}

This work is finically supported by the National Natural Science Foundation of China (No. 21671096, and No. 21603094), Natural Science Foundation of Guangdong Province (No. 2016A030310376), the Guangdong Special Support for the Science and Technology Leading Young Scientist (No. 2016TQ03C919), and the Basic Research Project of the Science and Technology Innovation Commission of Shenzhen (No. JCYJ20170412153139454 and No. JCYJ201708171102 51498).

\section{SUPPLEMENTARY MATERIAL}

The Supplementary Material for this article can be found online at: https://www.frontiersin.org/articles/10.3389/fchem. 2018.00270/full\#supplementary-material 


\section{REFERENCES}

Dahbi, M., Yabuuchi, N., Kubota, K., Tokiwa, K., and Komaba, S. (2014). Negative electrodes for Na-ion batteries. Phys. Chem. Chem. Phys. 16, 15007-15028. doi: $10.1039 / \mathrm{c} 4 \mathrm{cp} 00826 \mathrm{j}$

Duncan, H., Kondamreddy, A., Mercier, P. H. J., Page, Y. L., Abulebdeh, Y., Couillard, M., et al. (2016). Novel Pn polymorph for $\mathrm{Li}_{2} \mathrm{MnSiO}_{4}$ and its electrochemical activity as a cathode material in Li-Ion batteries. Chem. Mater. 23, 5446-5456. doi: $10.1021 / \mathrm{cm} 202793 j$

Fang, Y., Xiao, L., Qian, J., Cao, Y., Ai, X., Huang, Y., et al. (2016). Sodium Ion batteries: 3D graphene decorated NaTi2(PO4)3 microspheres as a superior high-rate and ultracycle-stable Anode material for sodium Ion batteries (Adv. Energy Mater. 19/2016). Adv. Energy Mater. 6:1502197. doi: 10.1002/aenm.201502197

Guin, M., and Tietz, F. (2015). Survey of the transport properties of sodium superionic conductor materials for use in sodium batteries. J. Power Sour. 273, 1056-1064. doi: 10.1016/j.jpowsour.2014.09.137

Hu, Q., Yu, M., Liao, J., Wen, Z., and Chen, C. (2018). Porous carbon-coated $\mathrm{NaTi}_{2}\left(\mathrm{PO}_{4}\right)_{3}$ with superior rate and low-temperature properties. J. Mater. Chem. A 6, 2365-2370. doi: 10.1039/C7TA10207K

Ha-Kyung, R., Hyun-Kyung, K., Myeong-Seong, K., Dong-Hyun, K., Kyung, Y. C., et al. (2016). In situ synthesis of chemically bonded $\mathrm{NaTi}_{2}\left(\mathrm{PO}_{4}\right)_{3} / \mathrm{rGO} 2 \mathrm{D}$ nanocomposite for high-rate sodium-ion batteries. Nano Res. 9, 1844-1855. doi: 10.1007/s12274-016-1077-y

Kim, K. C., Liu, T., Lee, S. W., and Jang, S. S. (2016). First-principles density functional theory modeling of Li Binding: thermodynamics and Redox properties of quinone derivatives for lithium-ion batteries. J. Am. Chem. Soc. 138, 2374-2382. doi: 10.1021/jacs.5b13279

Li, M., Liu, L., Wang, P., Li, J., Leng, Q., and Cao, G. (2017). Highly reversible sodium-ion storage in $\mathrm{NaTi}_{2}\left(\mathrm{PO}_{4}\right)_{3} / \mathrm{C}$ composite nanofibers. Electrochim. Acta 252, 523-531. doi: 10.1016/j.electacta.2017.09.020

Li, Z., Young, D., Xiang, K., Carter, W. C., and Chiang, Y. M. (2012). Towards High power high energy aqueous sodium-Ion batteries: the $\mathrm{NaTi}_{2}\left(\mathrm{PO}_{4}\right)_{3} / \mathrm{Na}_{0.44} \mathrm{MnO}_{2}$ system. Adv. Energy Mater. 3, 290-294. doi: 10.1002/aenm.201200598

Liang, J., Gao, X., Guo, J., Chen, C., Fan, K., and Ma, J. (2018a). Electrospun $\mathrm{MoO}_{2} @ \mathrm{NC}$ nanofibers with excellent $\mathrm{Li}^{+} / \mathrm{Na}^{+}$storage for dual applications. Sci. China Mater. 61, 30-38. doi: 10.1007/s40843-017-9119-2

Liang, J., Yuan, C., Li, H., Fan, K., Wei, Z., Sun, H., et al. (2018b). Growth of $\mathrm{SnO}_{2}$ nanoflowers on $\mathrm{N}$-doped carbon nanofibers as Anode for Li-and $\mathrm{Na}$-ion batteries. Nano Micro Lett. 10, 21. doi: 10.1007/s40820-017-0172-2

Liang, L., Sun, X., Wu, C., Hou, L., Sun, J., Zhang, X., et al. (2018). Nasicon-type surface functional modification in Core-Shell $\mathrm{LiNi}_{0.5} \mathrm{Mn}_{0.3} \mathrm{Co}_{0.2} \mathrm{O}_{2} @ \mathrm{NaTi}_{2}\left(\mathrm{PO}_{4}\right)_{3}$ Cathode Enhances its high-voltage cycling stability and rate capacity toward Li-Ion batteries. Acs Appl. Mater. Interfaces 10, 5498-5510. doi: 10.1021/acsami.7b15808

Liu, D., Zhang, X., Sun, Z., and You, T. (2013). Free-standing nitrogen-doped carbon nanofiber films as highly efficient electrocatalysts for oxygen reduction. Nanoscale 5, 9528-9531. doi: 10.1039/c3nr03229a

Ribero, D., Seymour, K. C., and Kriven, W. M. (2016). Synthesis of $\mathrm{NaTi}_{2}\left(\mathrm{PO}_{4}\right)_{3}$ by the Inorganic-Organic Steric Entrapment method and its thermal expansion behavior. J. Ame. Ceramic Soc. 99, 3586-3593. doi: 10.1111/jace. 14420

Stevens, D. A., and Dahna, J. R. (2000). High capacity anode materials for rechargeable Sodium-Ion batteries. J. Electrochem. Soc. 147, 1271-1273. doi: $10.1149 / 1.1393348$
Wang, D., Liu, Q., Chen, C., Li, M., Meng, X., Bie, X., et al. (2016). NASICONStructured $\mathrm{NaTi}_{2}\left(\mathrm{PO}_{4}\right)_{3} @ \mathrm{C}$ Nanocomposite as the low operation-voltage Anode material for high-performance Sodium-Ion batteries. ACS Appl. Mater. Interfaces 8, 2238-2246. doi: 10.1021/acsami.5b11003

Wang, P.-F., Yao, H.-R., Liu, X.-Y., Zhang, J.-N., Gu, L., Yu, X.-Q., et al. (2017). Ti-substituted $\mathrm{NaNi}_{0.5} \mathrm{Mn}_{0.5}-\mathrm{xTixO}_{2}$ cathodes with reversible O3-P3 phase transition for high-performance Sodium-Ion batteries. Adv. Mater. 29:1700210. doi: 10.1002/adma.201700210

Wang, Q., Xu, J., Zhang, W., Mao, M., Wei, Z., Cui, C., et al. (2018). Research progress on vanadium-based cathode materials for sodium ion batteries. $J$. Mater. Chem. A 6, 881-8838. doi: 10.1039/C8TA01627E

Wang, S., Cui, Z., and Cao, M. (2015). A template-free method for preparation of Cobalt Nanoparticles embedded in N-Doped carbon nanofibers with a hierarchical pore structure for oxygen reduction. Chemistry 21, 2165-2172. doi: 10.1002/chem.201404884

Wang, Y., Dong, L., Xiong, R., and Hu, A. (2013). Practical access to bandgap-like $\mathrm{N}$-doped carbon dots with dual emission unzipped from PAN@PMMA coreshell nanoparticles. J. Mater. Chem. C 1, 7731-7735. doi: 10.1039/c3tc30949e

Wu, C., Kopold, P., Ding, Y. L., Aken, P. A. V., Maier, J., and Yu, Y. (2015). Synthesizing Porous NaTi2(PO4)3 Nanoparticles embedded in 3D graphene networks for high-rate and long cycle-life sodium electrodes. ACS Nano 9, 6610-6618. doi: 10.1021/acsnano.5b02787

Wu, S., Wang, W., Li, M., Cao, L., Lyu, F., Yang, M., et al. (2016). Highly durable organic electrode for sodium-ion batteries via a stabilized $\alpha$-C radical intermediate. Nat. Commun. 7, 13318. doi: 10.1038/ncomms13318

Xu, J., Lee, D. H., Clément, R. J., Yu, X., Leskes, M., Pell, A. J., et al. (2017). Identifying the critical role of Li substitution in P2-Nax[LiyNizMn1-y-z] $\mathrm{O}_{2}(0$ $<\mathrm{x}, \mathrm{y}, \mathrm{z}<1$ ) Intercalation cathode materials for high-energy Na-Ion batteries. Chem. Mater. 26, 1260-1269. doi: 10.1021/cm403855t

Yang, J., Wang, H., Hu, P., Qi, J., Guo, L., and Wang, L. (2015). A highrate and ultralong-life Sodium-Ion battery based on $\mathrm{NaTi}_{2}\left(\mathrm{PO}_{4}\right)_{3}$ Nanocubes with synergistic coating of carbon and rutile $\mathrm{TiO}_{2}$. Small 11, 3744 . doi: $10.1002 /$ smll.201500144

Zhang, Q., Chen, H., Luo, L., Zhao, B., Luo, H., Han, X., et al. (2018), Harnessing the concurrent reaction dynamics in active Si and Ge to achieve high performance of lithium-ion batteries. Energy Environ. Sci. 11. 669-681. doi: $10.1039 / \mathrm{C} 8 \mathrm{EE} 00239 \mathrm{H}$

Zheng, Z., Zao, Y., Zhang, Q., Cheng, Y., Chen, H., Zhang, K., et al. (2018). Robust Erythrocyte-like $\mathrm{Fe}_{2} \mathrm{O}_{3} @$ carbon with Yolk-shell structures as highperformance Anode for Lithium Ion batteries. Chem. Eng. J. 347, 563-573. doi: 10.1016/j.cej.2018.04.119

Zhu, Q., Nan, B., Shi, Y., Zhu, Y., Wu, S., He, L., et al. (2017). $\mathrm{Na}_{3} \mathrm{~V}_{2}\left(\mathrm{PO}_{4}\right)_{3} / \mathrm{C}$ nanofiber bifunction as anode and cathode materials for sodium-ion batteries. J. Solid State Electrochem. 21, 1-11. doi: 10.1007/s10008-017-3627-y

Conflict of Interest Statement: The authors declare that the research was conducted in the absence of any commercial or financial relationships that could be construed as a potential conflict of interest.

Copyright $\odot 2018$ Yu, Wan, Shang, Wang, Zhou, Zou, Cheng and Lu. This is an open-access article distributed under the terms of the Creative Commons Attribution License (CC BY). The use, distribution or reproduction in other forums is permitted, provided the original author(s) and the copyright owner(s) are credited and that the original publication in this journal is cited, in accordance with accepted academic practice. No use, distribution or reproduction is permitted which does not comply with these terms. 